University of Wollongong

Research Online

Faculty of Social Sciences - Papers (Archive) Faculty of Arts, Social Sciences \& Humanities

$1-1-2017$

Effects of Integrating Physical Activities Into a Science Lesson on

Preschool Children's Learning and Enjoyment

Myrto F. Mavilidi

University of Wollongong, myrto@uow.edu.au

Anthony D. Okely

University of Wollongong, tokely@uow.edu.au

Paul A. Chandler

University of Wollongong, chandler@uow.edu.au

Fred Paas

University of Wollongong, fredp@uow.edu.au

Follow this and additional works at: https://ro.uow.edu.au/sspapers

Part of the Education Commons, and the Social and Behavioral Sciences Commons

Research Online is the open access institutional repository for the University of Wollongong. For further information contact the UOW Library: research-pubs@uow.edu.au 


\title{
Effects of Integrating Physical Activities Into a Science Lesson on Preschool Children's Learning and Enjoyment
}

\author{
Abstract \\ This study investigated the effects of physical activities that were integrated into a science lesson on \\ learning among preschool children. $A$ total of 90 children from seven childcare centres (Mage $=4.90, S D=$ \\ 0.52 ; 45 girls) were randomly assigned across an integrated physical activity condition including task- \\ relevant physical activities, a nonintegrated physical activity condition involving task-irrelevant physical \\ activities, or a control condition involving the predominantly conventional sedentary style of teaching. \\ Children learned the names of the planets and their order, based on the distance from the sun. For both \\ the immediate and delayed ( 6 weeks after the programme) assessments, results showed that learning \\ outcomes were highest in the integrated condition and higher in the nonintegrated condition than in the \\ control condition. Children in the integrated condition scored higher on perceived enjoyment of learning \\ than children in the control condition. Implications of integrated physical activity programmes for \\ preschool children's health, cognition, and learning are further discussed.

\section{Disciplines} \\ Education | Social and Behavioral Sciences

\section{Publication Details} \\ Mavilidi, M., Okely, A. D., Chandler, P. \& Paas, F. (2017). Effects of Integrating Physical Activities Into a \\ Science Lesson on Preschool Children's Learning and Enjoyment. Applied Cognitive Psychology, 31 (3), \\ 281-290.
}


Effects of Integrating Physical Activities into a Science Lesson on Preschool

Children's Learning and Enjoyment

\begin{abstract}
This study investigated the effects of physical activities that were integrated into a science lesson on learning among preschool children. A total of 90 children from seven childcare centres $\left(M_{\mathrm{age}}=4.90, S D=.52 ; 45\right.$ girls $)$ were randomly assigned across an integrated physical activity condition including task-relevant physical activities, a non-integrated physical activity condition involving task-irrelevant physical activities, or a control condition involving the predominantly conventional sedentary style of teaching. Children learnt the names of the planets and their order, based on the distance from the sun. For both the immediate and delayed (6 weeks after the program) assessments, results showed that learning outcomes were highest in the integrated condition, and higher in the non-integrated condition than in the control condition. Children in the integrated condition scored higher on perceived enjoyment of learning than children in the control condition. Implications of integrated physical activity programs for preschool children's health, cognition, and learning are further discussed.
\end{abstract}

Keywords: learning, science, preschool children, physical activity 
Effects of Integrating Physical Activities into a Science Lesson on Preschool

\section{Childrens' Learning and Enjoyment}

Young children are particularly enthusiastic about discovering the physical environment that surrounds them. Part of this interest stems from the tangible and specific ideas of concrete objects or animals - as opposed to abstract concepts - that are part of this environment. The first developmental theories of Piaget (1970) and Vygotsky (1962) emphasized the critical role of motor actions in human learning. When it comes to science learning, this is especially important as children have to abandon their beliefs or perceptions, and progress through a conceptual change in order to develop more complex representational structures (Carey, 2000). To this vein, physical experience through observation and manipulation appears to be essential for promoting young children's novel conceptual understanding in science (Gelman \& Brenneman, 2004; Zacharia, Loizou, \& Papaevripidou, 2012). For example, spatial thinking, which is critical to success in STEM disciplines, can be improved by the use of symbolic representations, analogies and gestures (Uttal, Miller, \& Newcombe, 2013). Intervention studies, using the theoretical framework of embodied cognition, have shown that physical experience, for example in the form of object manipulation, can embody knowledge and enhance learning of science (see e.g., Boncoddo, Dixon, \& Kelley, 2010; Kontra, Lyons, Fischer, \& Beilock, 2013; Lindgren \& Glenberg, 2013). Similar effects have been found in the domains of language (e.g., Mavilidi, Okely, Chandler, Cliff, \& Paas, 2015) and geography (Mavilidi, Okely, Chandler, \& Paas, 2016), when the knowledge was embodied through movements in the form of physical activities. In this study, we aimed to follow up on these studies by investigating the effects of infusing physical activities in preschool children's science learning on learning outcomes. 
Research on human movements can generally be categorised into studies including subtle movements such as gestures or studies including gross motor movements such as physical activity. Whereas the research on subtle movements mainly focuses on effects on cognition, research on physical activity mainly focuses on effects on health. The first part of this article presents the underlying theory and empirical evidence linking actions during learning (Madan \& Singhal, 2012; Moreau, 2015; Pouw, Van Gog \& Paas, 2014). In addition, the health and cognitive benefits of physical activity and how these benefits can be extended into education will be described (Owen et al., 2015; Sibley \& Etnier, 2003).

Perception and action are closely intertwined (Gallagher, 2005; Wilson, 2002). It is believed that cognition is grounded in different ways consisting of mental simulations, situated action, and bodily states. Movements play an essential role in learning and instruction (Ayres, Marcus, Chan, \& Qian, 2009). The body acquires a dominant role in cognition with a combination of perceptual, and sensorimotor experiences forming multimodal representations in memory (Barsalou, 2008; Barsalou, Simmons, Barbey, \& Wilson, 2003). These representations supply alternative routes for memory retrieval, because they are enriched with motor information (Madan \& Singhal, 2012; Plummer, 2009). The enactment effect was initially built upon the foundation that actions are better recalled when they are performed compared to when they are heard or read (Engelkamp \& Zimmer, 1989). Through embodied learning, embodiment, which refers to the enactment of concepts using the body, ranges from neuromuscular activation of low embodiment, in which only movements of fingers are involved, to high embodiment with full body movements engaged, relying on multimodal encoding methods to elicit higher retention and transfer of learning (Lindgren \& Johnson-Glenberg, 2013). Education 
researchers have proposed enactive metaphors during learning through whole-body movements as a way to instigate learning in science (Gallagher \& Lindgren, 2015). For instance, mixed reality environments use action-concepts congruencies where children can learn about laws of physics (e.g., gravitational force) by simulating the movements of asteroids in empty space or the orbits of planets by moving across floor-projected virtual environment, walking in a straight line, or moving faster or slower depending on children's distance to the planets (Lindgren \& JohnsonGlenberg, 2013; Lindgren \& Tscholl, Wang, \& Johnson, 2016). Comparing middle school students in an experimental condition, in which they were engaged in wholebody movements simulations, to a control condition using a desktop version of the simulation (i.e. movements by clicking a computer mouse), Lindgren et al. (2016) found that the learning gains as well as children's engagement levels were more pronounced in the experimental condition. Likewise, Plummer (2009) noted significant learning gains in the development of astronomy concepts in first and second grade students, through kinesthetic learning techniques in the planetarium, whereby they performed celestial trajectories with their bodies or objects representing stars and planets.

The importance of physical experience in science learning through engagement in whole body-movements is well accepted. However, it seems important to examine whether there is a relationship between the full-body movements in the form of physical activity and cognition. Physical activity can be defined as "any bodily movement produced by the contraction of skeletal muscle that can increase energy expenditure above a certain level, whereas exercise is considered as a "subcategory of physical activity that is planned, structured, and repetitive, focusing on the improvement or maintenance of one or more components of physical fitness, physical 
performance, or health" (Centre for Disease Control and Prevention, 2016). Research has gleaned insight into the association between physical activity and fitness with health benefits such as muscle and bone strengthening, better cardiometabolic health, prevention of chronic diseases (e.g., obesity, cholesterol, high blood pressure, type 2 diabetes, cardiovascular disease, cancer), reduction of depression and stress, better states of mood, and improved self-esteem and body image (Baranowski et al., 1992; Janssen \& LeBlanc, 2010; Penedo \& Dahn, 2005; Sothern, Loftin, Suskind, Udall, \& Blecker, 2010; Warburton, Nicol, \& Bredin, 2006; World Health Organization, 2015). Physical activity has also been related to cognitive benefits such as improved cerebral activity and enhanced brain development (e.g., better neural connections, improved blood flow and oxygenation), cognitive functioning (e.g., cognitive control, attention, and memory) and academic performance in children (Chaddock-Heyman et al., 2016; Drollette et al., 2014; Erickson, Hillman, \& Kramer, 2015; Fedewa \& Ahn, 2011; Hillman, Castelli, \& Buck, 2005; Kamijo, Takeda, Takai, \& Haramura, 2011; Khan \& Hillman, 2014; Rasberry et al., 2011; Sibley \& Etnier, 2003; Tomporowski, Davis, Miller, \& Naglieri, 2008). It is suggested that, in order to cultivate the potential for these salient benefits to occur, it should commence in early childhood education and care settings, widely recognised as a place for holistic learning characterised by physical, social and emotional development and determined by scaffolding of behavioural patterns (Barnett, 2008; Lu \& Montague, 2016).

Intervention programs to increase physical activity levels and positively affect academic achievement have been successfully established in elementary schools settings. These studies have incorporated classroom-based physical activities in the academic lessons of various learning areas such as maths, language, science, social sciences and general health (Donnelly \& Lambourne, 2011; Kibbe et al., 2011; Mahar 
et al. 2006; Mahar, 2011; Tarp et al., 2016). Based on these studies, Grieco, Jowers, Errisuriz, and Bartholomew (2016) focused on the dosage of physical activity intensity required to improve on-task behaviour. Results revealed that both a low dose of low-to moderate physical activity as well as a higher dose of moderate-to-vigorous physical activity can increase children's on-task behaviour compared to traditional sedentary more lessons. The magnitude of the effects shown were similar to Mahar et al. (2006). Finally, a series of studies objectively measuring physical activity and learning outcomes in preschool children found improvements in academic performance and increase in physical activity levels during learning of foreign language vocabulary and geography combined with whole-body movements (Mavilidi et al., 2015, 2016).

The current study will assess the effects of whole-body movements on preschool children's learning in science by objectively gauging learning and physical activity outcomes. A solar system task was chosen for preschool children as a foundational introduction in the domain of science. More complex and developed concepts such as the celestial motion (how the sun, the moon and the stars move) are considered as an acquired knowledge for children in early elementary school (Benchmarks; AAAS, 1994; Plummer, 2009).

In this study, three experimental conditions will engage children in a solar system task combined with meaningful physical activities, non-related physical activities, or without physical activities included. In the integrated condition, children will perform movements related to the learning content. In this condition, children will run starting from the position of the sun to the closest planet (i.e., Mercury). In the non-integrated condition, movements will be unrelated to the task and children will run around the classroom for several minutes. Finally, the control condition will 
represent the conventional way of teaching, in which children will stay seated and observe the planets. It is expected that the conditions that include movements (integrated and non-integrated condition) will outperform the control condition (Hypothesis 1). Moreover, based on the combined embodied and physiological effects, it is assumed that the integrated condition will show the highest learning outcomes (Hypothesis 2). Finally, children in each condition will evaluate how much they enjoyed the way they learned. It is hypothesised that the integrated condition will show the highest scores for perceived enjoyment of the learning method (Hypothesis $3)$.

\section{Method}

\section{Participants}

This study was approved by the Human Research Ethics Committee of the University of Wollongong (HE15/458). Seven early childhood centres from the Illawara area of NSW, Australia were included in this study (See Figure 1). Each centre director and the child's parents provided their written consent forms for their children's participation in the study. A total of 90 typically developing children (no diagnosis of mental illness, disorders, or learning difficulties) participated in this study $\left(M_{\mathrm{age}}=4.90, S D=.52 ; 45\right.$ girls; $2.3 \%$ Aboriginal, $1.1 \%$ for American, French, Indian, Indonesian, Irish, Vietnamese, Russian, Spanish, Serbian, 2.3\% British, 3.4\% Chinese). The existence of low income Health Care Card or pension card from Centrelink was used as an index of socioeconomic status (SES; Australian Government Department of Human Rights, 2016). The index indicated that the population of this study consisted of mainly medium to high socioeconomic status. There were no differences among the conditions in terms of demographic characteristics (Table 1). Three children were excluded from the analyses because of a 
general reluctance to participate and 1 child due to missing data. Randomization occurred at centre level and per condition (each centre was aligned to one/several different conditions), resulting in 30 enrolled in the integrated condition, 27 in the non-integrated condition, and 29 in the control condition. Stickers were given as a reward for children's effort at the end of each learning and testing session.

\section{Procedure and Materials}

The researcher visited the childcare centres and coordinated the learning and testing sessions. The learning sessions consisted of a solar system task (i.e., name of planets and their right order based on their distance from the sun). The learning sessions took place in small groups (max 10 children), once per week, for four weeks. The testing session occurred individually at three time points: a pre-test was administered before the first learning session to assess children's prior knowledge, an immediate post-test directly after the end of the last learning session, and a delayed post-test 6 weeks after the last learning sessions. The two post-tests determined the knowledge children had acquired during the learning sessions.

During the learning sessions, a picture of the sun and the planets in space (on a straight line) was placed at a central point easily to be seen by all children. Also, "toy" planets were placed in a line on the floor in the same order, corresponding to the planets in the pictures. Children had to remember the names of the planets and their correct order starting from the planet closest to the sun, Mercury, through to the planet furthest from the sun, Neptune. The instructor began with a small introduction of the concept of space and the planets.

Children were assigned to a condition at a centre level. However, some centres were enrolled in more than one condition. In these cases, each group ran on different 
days with different children and at the completion of the previous group to avoid contamination of the conditions. The instructor called aloud the name of the planets in all conditions. In the integrated condition, children performed physical activities related to the learning task. Starting from the sun, they visited the first planet and then they returned back to the sun. Then, they visited the second planet, and returned back to the Sun. They did the same actions for all the planets. In the non-integrated condition, children performed physical activities unrelated to the learning task. Firstly, children ran a lap around the room. Then, they sat and listened to all the names of the planets. They followed the same process three times. In the control condition, no physical activities were involved. Children remained seated while observing the planets (the first planet was the one closer to the sun until the one furthest from the sun). During each learning session, which lasted 10 min per day for all conditions, the names of the planets were repeated three times in all conditions.

During the testing sessions, children were evaluated on their ability to recall the names of the planets and their appropriate order starting from Mercury. The cognitive tests included:

Free-recall test: children were asked to name any planet they could remember. Next, they were asked to place the toys planets in a straight line, starting with Mercury and finishing with Neptune.

Cued-recall test: children were shown pictures of four planets and were asked to name them (i.e., Venus, Mars, Earth, Uranus). Also, children were given four toy planets and were asked to place them in the right order based on their distance from the sun, starting with the planet that is closest to the sun (i.e., Mercury, Jupiter, 
Saturn, Neptune). Finally, children were shown four toy planets and were asked to name them (i.e., Mercury, Earth, Uranus, Neptune).

Children received one point for each correct answer. The maximum score that children could get was 28. This method was based on Best, Dockrell, and Braisby's (2006) method to evaluate older children's knowledge about the eclipse and entities related to space. A reliability coefficient (Cronbach's alpha) of .84 was found for the testing materials.

Physical activity was objectively assessed using accelerometers (model GT1M, Pensacola, FL). The sampling interval (epoch) was set at 1 second to best capture variability in children's activity (Cliff, Reilly, \& Okely, 2009). Parents (via written consent forms) were informed that their children would wear the accelerometer during the learning sessions. Accelerometers were affixed to an elastic belt and placed by trained staff around the child's waist so that the accelerometer was at the top of their right hip at the beginning of the lesson and were removed at the end of the lesson. Accelerometers were processed using ActiLife v6.12.1 software and were recorded for the scheduled 10-min period. The time spent per lesson in various intensities was calculated using child-specific cut-points (Pate, Almeida, McIver, Pfeiffer, \& Dowda, 2006). These cut-points have been shown to be the most accurate in young children (Janssen et al., 2013). Data were reported as minutes spent in moderate-to-vigorousintensity physical activity, and the average activity counts per minute, representing the total activity intensity during the lesson.

At the end of the immediate post-test and delayed post-test, children evaluated how much they liked the type of instruction ("Did you like this game"), and if they would like to be taught this way in the future ("Would you like to play it again in the 
future?") on a 5-point Likert scale with response scores ranging from 1, "I didn't like it all", to 5, "I liked it a lot", and 1, "Not at all" to 5, "I would love to", respectively. These were supplemented with a visual scale of smiley faces ranging from 1 to 5 , corresponding to the two questions. The interest ratings were computed as the average scores on these questions. This scale was adapted from the study of Mavilidi et al. (2016). A coefficient alpha of .85 was obtained for these questions in this study.

\section{Statistical Analyses}

A randomised control trial was conducted to assess the effectiveness of the suggested instructional approaches on children's learning outcomes and children's interest after the intervention. Physical activity outcomes were included in the analyses to confirm our basic assumption that children would be more physically active in the physical activity conditions (integrated and non-integrated), than in the sedentary control condition. To control for baseline differences in demographic characteristics among the conditions (age, gender, ethnicity, socioeconomic status), an ANOVA and Chi-Square Tests were used. Separate analyses were conducted for the learning outcomes, interest ratings for the instructional method, and physical activity outcomes. With regard to the learning outcomes, a cluster design was chosen initially since the intervention was structured in 7 childcare centres, where childcare centre was treated as a random variable with children nested in preschools and in conditions (integrated vs. non-integrated vs. control). The childcare centre, children's ethnicity, socioeconomic status, and gender were set as the cluster units for the randomization. Because the analyses produced similar results and none of the demographics characteristics seem to be a confounder, we chose to perform a mixed 3 (Condition: integrated physical activity, non-integrated physical activity, control) x 2 (Time of 
Testing: immediate post-test, delayed post-test) experimental design with repeatedmeasures on the latter factor, accounting for possible interaction effects. The independent variables were condition and time of testing, and the covariate was children's pre-test scores. The same experimental design was used to look for differential effects of condition on children's interest scores (excluding the covariate).

Finally, the differences in physical activity outcomes among the conditions were examined in two separate analyses for counts per minute, and time spent in moderate-to-vigrorous intensity physical activity.

The datasets were controlled for outliers, normality of the distribution, homogeneity of variance, and sphericity (when required; Field, 2009). The analyses were performed using SPSS and STATA. The significance level was set at .05 and Eta-squared $\eta^{2}$ was used as an estimate of effect size, with $\eta^{2}=.02$ corresponding to a small effect, $\eta^{2}=.13$ corresponding to a moderate effect, and $\eta^{2}=.26$ corresponding to a large effect (Cohen, 1988, 2013).

\section{Results}

\section{Learning outcomes}

An analysis of variance (ANOVA) was run before the main analysis. This analysis yielded no significant differences among the conditions in the pre-test scores, $F(2,84)=.08, p=.922$ (integrated condition, $M=1.58, S E=.38,95 \%$ CI .82-, 2.34, non-integrated condition, $M=1.37, S E=.41,95 \%$ CI $.56-2.18$, control condition, $M$ $=1.55, S E=.39,95 \% \mathrm{CI} .77-2.33)$.

Results from the mixed ANCOVA revealed that the covariate, pre-test scores, had a significant effect on learning scores, $F(1,82)=12.44, p \leq .001, \eta^{2}=.13$. After controlling for the covariate, pre-test scores, there were significant main effects of 
condition, $F(2,82)=34.98, p \leq .001, \eta_{\mathrm{p}}^{2}=.46$, and time of testing, $F(1,82)=16.15$, $p \leq .001, \eta_{\mathrm{p}}^{2}=.17$, on learning performance. Although the interaction between time of testing and the covariate, pre-test scores, was not significant, $F(1,82)<1, p=.177$, the main effects were qualified by a significant interaction between condition and time of testing, $F(2,82)=6.17, p=.003, \eta_{\mathrm{p}}^{2}=.13$. Post hoc comparisons with Bonferroni correction, controlling for Type I error, revealed that the integrated condition $(M=14.05, S E=.73,95 \%$ CI $12.59-15.51)$ performed better than the nonintegrated $(M=10.11, S E=.78,95 \%$ CI $8.56-11.65, p \leq .001)$ and control condition $(M=5.28, S E=.75,95 \%$ CI $3.79-6.77, p \leq .001)$. Also, the non-integrated $(p \leq .001)$ and control condition $(p \leq .001)$ significantly differed. Table 2 presents descriptive statistics for science scores for all conditions during the two time points of testing.

Furthermore, pairwise comparisons with Bonferonni correction showed that children performed better in the immediate post-test $(M=10.71, S E=.48,95 \% \mathrm{CI}$ 9.75-11.67), $p \leq .001$ than the delayed post-test $(M=8.91, S E=.44,95 \%$ CI $8.04-$ $9.79, p \leq .001)$.

\section{Interest ratings for instructional method}

A mixed analysis of variance (ANOVA) was run to assess children's interest across the conditions. The interest ratings were measured at two moments, directly after the end (immediate post-test) and six weeks after the intervention (delayed posttest). Table 2 presents descriptive statistics for children's interest for the three conditions during the two time points of testing. The analysis revealed that the main effect of time of testing was not significant, $F(1,83)=1.98, p=.164$. However, there was a significant main effect of condition, $F(2,83)=7.43, p \leq .001, \eta_{p}^{2}=.15$. The interaction between condition and time of testing was not significant, $F(2,83)=1.34$, 
$p=.267$. With regard to the main effect of condition, post-hoc comparisons revealed that children in the integrated condition $(M=4.36, S E=.16,95 \%$ CI 4.05-4.67) gave higher ratings for enjoyment of their way of learning than children in the control condition $(M=3.49, S E=.16,95 \%$ CI $3.17-3.81, p s \leq .001)$ did for their specific way of learning. However, the ratings in the non-integrated condition $(M=3.94, S E=.17$, 95\% CI 3.61-4.28) did not differ from ratings in the integrated condition $(p=.075)$, and control condition $(p=.053)$.

\section{Physical activity outcomes}

An ANOVA was performed to assess the intensity levels of physical activity across the conditions, with counts per minute as dependent variable, and condition as independent variable. Results showed a significant effect of condition on counts per minute, $F(2,215)=26.13, p \leq .001, \eta_{\mathrm{p}}^{2}=.19$. Post hoc comparisons with Hochberg correction, controlling for different sample sizes, revealed that children in the nonintegrated condition $(M=1117.00, S E=53.57,95 \%$ CI 1011.42-1222.59) were more physically active than children in the integrated condition $(M=878.23, S E=53.57$, 95\% CI 780.85-975.61, $p=.004)$. Children in the integrated and non-integrated condition were more physically active than children in the control condition $(M=$ 530.27, $S E=61.04,95 \%$ CI 409.96-650.57, both $p \mathrm{~s} \leq .001)$.

Moreover, an ANOVA was performed on the total time spent in moderate to vigorous physical activity (MVPA), with condition as the independent variable. Results showed that there was a significant effect of condition on time spent in MVPA, $F(2,215)=40.92, p \leq .001, \eta_{\mathrm{p}}^{2}=.27$. Post hoc comparisons with GamesHowell correction, controlling for unequal variances, showed that children in the nonintegrated condition $(M=2.25, S E=.09,95 \%$ CI 2.06-2.43) spent more time in 
MVPA than children in the integrated condition $(M=1.62, S E=.09,95 \%$ CI $1.46-$ $1.79, p \leq .001)$. Moreover, children in the integrated and non-integrated condition spent more time in MVPA than children in the control condition $(M=.98, S E=.11$, 95\% CI .77-1.19, both $p$ s $\leq .001)$.

\section{Discussion}

The purpose of this study was to investigate the learning effects of integrating physical activities into a science lesson among preschool children. The results confirmed the hypotheses, indicating that the integrated physical activity condition, in which children embodied science knowledge through physical activities, had the highest learning outcomes, assessed by a combination of free-recall and cued-recall tests directly after and six weeks after the end of the intervention. In addition to that, the non-integrated condition, which involved task-irrelevant movement, performed better than the sedentary control condition (Hypothesis 1). The outcomes of this study reflect the effects of task-relevant whole and part-body movements on learning outcomes found in past research (Boncoddo, Dixon, \& Kelley, 2010; Donnelly \& Lambourne, 2011; Gallagher \& Lindgren, 2015; Mavilidi et al., 2015, 2016). Intervention studies attest the importance of the use of body movements, specifically for science learning. For example, Kontra, Lyons, Fischer, and Beilock (2015) evaluated the importance of physical experience in science learning in college students. Through a series of studies, students learned about the vector nature of angular momentum. Firstly, during the training, they observed avatars on videos and afterwards they were paired to an action group in which they had to physically manipulate aspects of a wheel system (e.g., direction, spin, speed, size, and tilt), or an observation group in which they could observe the tilting and the path of a red laser 
dot on the wall. The test trials included wheels spun in the same and opposite directions to those in the training sessions. Also, the neural correlates of the learning path of the participants were recorded using functional magnetic resonance imaging (fMRI). Finally, it was examined whether the effects of action experience would remain after several days of engagement in the bicycle-wheel system. It was found that students who were able to physically manipulate the angular momentum outperformed students who only observed the same phenomena. Action experience activated their sensorimotor brain systems and fostered their understanding of the physics concepts. Moreover, Boncoddo et al. (2010) examined whether meaningful hand movements had an effect on preschool children's learning of simple gear-system problems. Firstly, children familiarised themselves with the properties of the gears by physically manipulating toy gears and then they solved the gear-system problems on a computer. Results displayed that, when children used a force-tracing strategy (i.e., by choosing which clockwise-counterclockwise motions they had to make to solve how gears alternate turning direction), they were able to solve the gear problems faster. The interaction between children's movements and the gear system enabled them to acquire novel representations of physics from their own actions.

Importantly, the essential role of physical experience and linking knowledge to real-world examples during science learning is emphasised for improving spatial abilities (Hegarty \& Waller, 2005), the construction of mental representations and richer cognitive schemas, memory encoding, retention and retrieval, and learning (Madan \& Singhal, 2012; Zacharia, Loizou, \& Papaevripidou, 2012). Mental imagery is a fundamental key element for understanding and learning of science in students (Leutner, Leopold, \& Sumfleth, 2009). The explicit connections between experiences and representations as well as the high level of familiarity of the scientific concepts 
enhanced children's learning (Enyedy, Danish, Delacruz, \& Kumar, 2012). The dynamic imagery arising from the multimodal representations and use of analogies during science learning is consistent with the "embodied cognition" notion, advocating that people learn from the interaction of their body with their physical environment (Gallagher, 2005; Wilson, 2002). Engaging preschool children's cognitive and motor skills is pivotal for their future development ( $\mathrm{Lu} \&$ Montague, 2015). Strong empirical evidence attests the positive associations of physical activity and exercise on cognition and academic achievement during childhood (ÁlvarezBueno et al., 2016; Hillman \& Biggan, 2016; Khan \& Hillman, 2014). The fact that children in the non-integrated physical activity condition had higher learning outcomes than the control condition provides proof in favor of this argument (Hypothesis 2).

Two previous studies conducted in preschool children, utilizing the physiological benefits of physical activity combined with the attributes from embodied learning, and incorporating short interventions of $10-20$ min weekly with combined physical and cognitive activities during insruction in different learning domains replicate the main findings found here (Mavilidi et al., 2015, 2016). Mavilidi et al. (2015) targeted foreign language vocabulary learning conducted 15-20 min, twice per week for 4 weeks, when children were randomly assigned to four conditions: in the integrated condition, they performed physical activities related to the meaning of the words (e.g., dancing for the word "dance"). In the non-integrated condition, they were engaged in physical activities irrelevant to the meaning of the word (i.e., running for each word). In the gesturing condition, children remained seated and gestured related to the meaning of the word (e.g., rhythmic hand movements for the word "dance"). Finally, in the conventional condition, children 
remained seated and repeated the words with no movements involved. Results showed that the children in the integrated condition had the highest scores on freerecall and cued-recall tests, and that children in both the non-integrated and gesturing condition outperformed the children in the conventional condition on the cued-recall test. Children's physical activity levels were equal in the physical activity groups (integrated and non-integrated condition) but higher compared to the gesturing and conventional condition. Finally, in Mavilidi et al. (2016), children attended three learning sesions of 10 min per day while learning geography (i.e., the continents and characteristics animals living in each continent), and were randomly assigned to three experimental conditions: in the integrated condition, physical activities were linked with the information to-be-learned such as hopping like a kangaroo from Oceania; the non-integrated condition, in which physical activities were irrelevant to the information such as runnning around the map, and a control condition, where children remained seated and listened to the information to-be-learned. The physical activity groups outperformed the control condition whereas children in the non-integrated condition were more physically active than children in the integrated and in the control condition. Both studies suggested that active learning through the integration of physical activities with academic content has the potential to enhance preschool children's learning performance, with effects found when instruction was conducted in groups (Mavilidi et al., 2015) as well as individually (Mavilidi et al., 2016).

In addition, although we were expecting children in the physical activity groups (integrated and non-integrated condition) to be involved in the same levels of physical activity, this was not found to hold true in this case. This study corroborates the findings of physical activity measurements from Mavilidi et al. (2016) and can be attributed to the type and nature of the learning task. Children in the non-integrated 
condition in both studies had to run around (the planets and the map respectively), and consequently covered a greater distance compared to children in the integrated condition. It is possible that higher physical activity intensity levels for the integrated condition would contribute to even higher learning scores, but this needs to be examined in future research.

Nevertheless, it is likely that children did not enjoy the physical activity aspect unrelated to the task as they evaluated it the same as in the control condition, in which children remained seated and observed the planets. Conversely, they showed higher levels of enjoyment in the integrated condition as they evaluated it higher than the control condition, partly confirming Hypothesis 3. Existing literature supports that collaborative learning (Shoval, 2011) and classroom based-physical activity programs (Vazou \& Smiley-Oyen, 2014) can enhance children's motivation and enjoyment.

In summary, this is the first experiment to include objective measurements of both physical activity and learning outcomes in preschool children's science learning. It adds to the existing body of research indicating how physical activity interventions can positively affect cognitive functioning and academic performance in children (Diamond, 2015; Diamond \& Lee, 2011; Schmidt, Benzing, \& Kamer, 2016; Vazou, Pesce, Lakes, \& Smiley-Oyen, 2016). The effects are more pronounced when these interventions include cognitively engaging activities during learning. In the present study, children in the integrated condition seemed to have benefited from the combined embodied and physical activity effects. In addition to this, children might have benefited not only from making movements but also from observing others' movements. In accordance with research on the "mirror neuron system", looking at other's actions may activate the same neurons related to these actions in the motor cortex (Rizzolatti \& Craighero, 2004). The mirroring capacity can be transferred 
during learning of cognitive tasks including a motor component (Paas \& Sweller, 2012; Van Gog, Paas, Marcus, Ayres, \& Sweller, 2009). Future research should shed light on the effects of performing and observing physical activities on learning occurring in groups and/or individual sessions as well as isolating the effects of embodiment and physical activity, motivation, and cooperative learning.

Future research is also recommended to investigate the effectiveness and efficacy of classroom-based physical activity programs with different target groups such as adolescents, and different learning contents related to science, as well as the generalisability of outcomes to more compex cognitive tasks. In addition, intervention studies at larger scale and for more prolonged periods would be needed to capture the long-term effects of physical activity, related to the possible changes in body mass index and physical fitness, on preschool children's cognition and learning, allowing us to be more conclusive in an area of research which is currently scarce. So far, it has been shown that single bouts of physical activity (acute exercise) can provoke physiological arousal facilitating the available attentional resources and engagement of cognitive functioning whereas multiple bouts (chronic exercise) alternate morphologically brain regions responsible for learning (Best, 2012; Brisswalter, Collardeau, \& René, 2002; Tomporowski et al., 2008).

Finally, this study took into account the nested nature of data as well as participants' demographics characteristics. Although no significant differences were found among the conditions, a stricter criterion during randomization would be advisable in future research to control for potential confounders.

In conclusion, this study places science learning in early childhood - an area where there has been little research - at the centre of attention. However, children usually face challenges with deeper understanding of concepts of science. Best, 
Dockrell, and Braisby (2006) assessed the knowledge of children from ages 4 to 8 years old on science and more specifically on their knowledge about the concept of eclipse and entities related to space (i.e., sun, moon, earth, planets). Their aim was to examine what children were able to understand about science and at what level their mental representations of space correspond with those of adults. It was found that children were able to acquire new words or concepts as abstract as space but not as accurately as adults. Even though children obtained knowledge about solar eclipse, the concept of lunar eclipse was more difficult for them. Nevertheless, children's interest and knowledge in science commence well before formal schooling. This study suggests a promising, and entertaining way to promote the acquisition of fundamental concepts during science learning (i.e., the solar system), knowledge that is required by young children when entering school (Benchmarks; AAAS, 1994; Plummer, 2009). Early exposure and familiarisation to the contents of science are the foundational basis for learning (Trundle, 2015), rendering them as the backbone for STEM learning and future related careers.

Overall, the present study suggests a promising instructional approach that has the potential to offer significant physical, psychological, and cognitive gains. Notable changes were detected only within a short intervention of $1 \mathrm{~h}$ in total. We think that longer periods will offer even more pervasive results, but this needs to be confirmed in future research. This innovative method is easy to implement, requires little additional resources or equipment, and can be adjusted to teachers' restrictions and demands during daily routines. At the same time, it can foster academic achievement through higher engagement and performance, while compensating for the loss in academic time that is characteristic for normal physical activity lessons that are not integrated with learning (Sallis et al. 1997; Ward et al., 2006). Notably, taking into 
account the increment of overweight preschool children (Ogden et al., 2006), who are less active in the childcare centres compared to their normal counterparts (Trost, Sirard, Dowda, Pfeiffer, \& Pate, 2003), initiating physical activity into classroombased programs would result in a concomitant increase in children's daily physical activity intensity levels. In turn, infusing physical activity with learning tasks would bring preschool children closer to the suggested 3 hours per day of physical activity recommendations (Australian Government Department of Health, 2014; Tremblay et al., 2002), leading to a healthier lifestyle and well-being in the long-term. 


\section{References}

Álvarez-Bueno, C., Pesce, C., Cavero-Redondo, I., Sánchez-López, M., PardoGuijarro, M. J., \& Martínez-Vizcaíno, V. (2016). Association of physical activity with cognition, metacognition and academic performance in children and adolescents: a protocol for systematic review and meta-analysis. $B M J$ Open, 6(6), 1-7. doi: 10.1136/bmjopen-2016-01106

American Association for the Advancement of Science. (1994). Benchmarks for science literacy. New York: Oxford University Press.

Australian Government Department of Health (2014). Australia's physical activity and sedentary behaviour guidelines. Retrieved from: http://www.health.gov.au/internet/main/publishing.nsf/content/health-pubhlthstrateg-phys-act-guidelines\#npa05

Australian Government Department of Human Rights (2016). Concession and health care cards. Retrieved from:

https://www.humanservices.gov.au/customer/subjects/concession-and-healthcare-cards

Ayres, P., Marcus, N., Chan, C., \& Qian, N. (2009). Learning hand manipulative tasks: When instructional animations are superior to equivalent static representations. Computers in Human Behavior, 25(2), 348-353. doi: 10.1016/j.chb.2008.12.013

Barsalou, L. W. (2008). Grounded cognition. Annual Review of Psychology, 59, 617645. doi: 10.1146/annurev.psych.59.103006.093639 
Barsalou, L. W., Simmons, W. K., Barbey, A. K., \& Wilson, C. D. (2003). Grounding conceptual knowledge in modality-specific systems. Trends in Cognitive Sciences, 7(2), 84-91. http://dx.doi.org/10.1016/S1364-6613(02)00029-3

Baranowski, T., Bouchard, C., Bar-Or, O., Bricker, T., Heath, G., Kimm, S. Y. S., Malina, R., Obarzanek, E., Pate, R., Strong, W. B., Truman, B., \& Washington, R. (1992). Assessment, prevalence, and cardiovascular benefits of physical activity and fitness in youth. Medicine and Science in Sports and Exercise, 24(6), S237-S247.

Barnett, W. S. (2008). Preschool education and its lasting effects: Research and policy implications. Great Lakes Center for Education Research \& Practice.

Best, R. M., Dockrell, J. E., \& Braisby, N. R. (2006). Real-world word learning: Exploring children's developing semantic representations of a science term. British Journal of Developmental Psychology, 24(2), 265-282. doi: $10.1348 / 026151005 X 36128$

Best, J. R. (2010). Effects of physical activity on children's executive function: Contributions of experimental research on aerobic exercise. Developmental Review, 30(4), 331-351. doi: 10.1016/j.dr.2010.08.001

Boncoddo, R., Dixon, J. A., \& Kelley, E. (2010). The emergence of a novel representation from action: evidence from preschoolers. Developmental Science, 13(2), 370-377. doi: 10.1111/j.1467-7687.2009.00905.x

Brisswalter, J., Collardeau, M., \& René, A. (2002). Effects of acute physical exercise characteristics on cognitive performance. Sports Medicine, 32(9), 555-566. doi:10.2165/00007256-200232090-00002 
Carey, S. (2000). Science education as conceptual change. Journal of Applied Developmental Psychology, 21(1), 13-19. doi: 10.1016/S01933973(99)00046-5

Centre for Disease Control and Prevention. Physical activity. Glossary of terms. Retrieved, November, 10, 2016, from: http://www.cdc.gov/physicalactivity/basics/glossary/index.htm

Chaddock-Heyman, L., Erickson, K. I., Chappell, M. A., Johnson, C. L., Kienzler, C., Knecht, A., Drollette, E. S., Raine, L. B., Scudder, M. R, Hao, S.- C., Hillman, C. H., Kramer, A. F. (2016). Aerobic fitness is associated with greater hippocampal cerebral blood flow in children. Developmental Cognitive Neuroscience, 20, 52-58. http://dx.doi.org/10.1016/j.den.2016.07.001

Cliff, D. P., Reilly, J. J., \& Okely, A. D. (2009). Methodological considerations in using accelerometers to assess habitual physical activity in children aged 0-5 years. Journal of Science and Medicine in Sport, 12(5), 557-567. http://dx.doi.org/10.1016/j.jsams.2008.10.008

Cohen, J. (1988). Statistical power analysis for the behavioral sciences (2nd ed.). Hillsdale: Erlbaum.

Cohen, J. (2013). Statistical power analysis for the behavioral sciences. Routledge Academic.

Diamond, A. (2015). Effects of physical exercise on executive functions: going beyond simply moving to moving with thought. Annals of Sports Medicine and Research, 2(1), 1-5. 
Diamond, A., \& Lee, K. (2011). Interventions shown to aid executive function development in children 4 to 12 years old. Science, 333(6045), 959-964. doi: $10.1126 /$ science. 1204529

Donnelly, J. E., \& Lambourne, K. (2011). Classroom-based physical activity, cognition, and academic achievement. Preventive Medicine, 52, S36-S42. http://dx.doi.org/10.1016/j.ypmed.2011.01.021

Drollette, E. S., Scudder, M. R., Raine, L. B., Moore, R. D., Saliba, B. J., Pontifex, M. B., Hillman, C. H. (2014). Acute exercise facilitates brain function and cognition in children who need it most: An ERP study of individual differences in inhibitory control capacity. Developmental Cognitive Neuroscience, 7, 53-64. doi: 10.1016/j.den.2013.11.001

Enyedy, N., Danish, J. A., Delacruz, G., \& Kumar, M. (2012). Learning physics through play in an augmented reality environment. International Journal of Computer-Supported Collaborative Learning, 7(3), 347-378. doi: $10.1007 / \mathrm{s} 11412-012-9150-3$

Erickson, K. I., Hillman, C. H., \& Kramer, A. F. (2015). Physical activity, brain, and cognition. Current Opinion in Behavioral Sciences, 4, 27-32. doi: 10.1016/j.cobeha.2015.01.005

Engelkamp, J., \& Zimmer, H. D. (1989). Memory for action events: A new field of research. Psychological Research, 51(4), 153-157. doi: 10.1007/BF00309142

Fedewa, A. L., \& Ahn, S. (2011). The effects of physical activity and physical fitness on children's achievement and cognitive outcomes: a meta-analysis. Research 
Quarterly for Exercise and Sport, 82(3), 521-535.

http://dx.doi.org/10.1080/02701367.2011.10599785

Field, A. (2009). Discovering statistics using SPSS. Sage publications

Gallagher, S. (2005). How the body shapes the mind (pp. 173-178). Oxford: Clarendon Press.

Gallagher, S., \& Lindgren, R. (2015). Enactive metaphors: learning through full-body engagement. Educational Psychology Review, 27(3), 391-404. doi: $10.1007 / \mathrm{s} 10648-015-9327-1$

Gelman, R., \& Brenneman, K. (2004). Science learning pathways for young children. Early Childhood Research Quarterly, 19(1), 150-158. http://dx.doi.org/10.1016/j.ecresq.2004.01.009

Grieco, L. A., Jowers, E. M., Errisuriz, V. L., \& Bartholomew, J. B. (2016). Physically active vs. sedentary academic lessons: A dose response study for elementary student time on task. Preventive Medicine, 89, 98-103. http://dx.doi.org/10.1016/j.ypmed.2016.05.021

Hegarty, M., \& Waller, D. (2005). Individual differences in spatial abilities. The Cambridge handbook of visuospatial thinking, 121-169.

Hillman, C. H., \& Biggan, J. R. (in press). A review of childhood physical activity, brain, and cognition: Perspectives on the future. Pediatric Exercise Science. doi: http://dx.doi.org/10.1123/pes.2016-0125

Hillman, C. H., Castelli, D. M., \& Buck, S. M. (2005). Aerobic fitness and neurocognitive function in healthy preadolescent children. Medicine \& 
Science in Sports \& Exercise, 37(11), 1967-1974. doi:

10.1249/01.mss.0000176680.79702.ce

Janssen, X., Cliff, D. P., Reilly, J. J., Hinkley, T., Jones, R. A., Batterham, M., Ekelund, U., Brage, S., \& Okely, A. D. (2013). Predictive validity and classification accuracy of ActiGraph energy expenditure equations and cutpoints in young children. PLoS ONE, 8(11), 1-9. e79124.http://dx.doi.org/10.1371/journal.pone.0079124

Janssen, I., \& LeBlanc, A. G. (2010). Systematic review of the health benefits of physical activity and fitness in school-aged children and youth. International Journal of Behavioral Nutrition and Physical Activity, 7(40), 1-16. doi: $10.1186 / 1479-5868-7-40$

Kamijo, K., Takeda, Y., Takai, Y., \& Haramura, M. (2015). Greater aerobic fitness is associated with more efficient inhibition of task-irrelevant information in preadolescent children. Biological Psychology, 110, 68-74. doi: 10.1016/j.biopsycho.2015.07.007

Khan, N. A., \& Hillman, C. H. (2014). The relation of childhood physical activity and aerobic fitness to brain function and cognition: A review. Pediatric Exercise Science, 26(2), 138-146. http://dx.doi.org/10.1123/pes.2013-0125

Kibbe, D. L., Hackett, J., Hurley, M., McFarland, A., Schubert, K. G., Schultz, A., \& Harris, S. (2011). Ten Years of TAKE 10!®: Integrating physical activity with academic concepts in elementary school classrooms. Preventive Medicine, 52, S43-S50. http://dx.doi.org/10.1016/j.ypmed.2011.01.025 
Kontra, C., Lyons, D. J., Fischer, S. M., \& Beilock, S. L. (2015). Physical experience enhances science learning. Psychological Science, 26(6), 737-749. doi: $10.1177 / 0956797615569355$

Leutner, D., Leopold, C., \& Sumfleth, E. (2009). Cognitive load and science text comprehension: Effects of drawing and mentally imagining text content. Computers in Human Behavior, 25(2), 284-289. doi:10.1016/j.chb.2008.12.010

Lindgren, R., \& Johnson-Glenberg, M. (2013). Emboldened by embodiment six precepts for research on embodied learning and mixed reality. Educational Researcher, 42(8), 445-452. doi: 10.3102/0013189X13511661

Lindgren, R., Tscholl, M., Wang, S., \& Johnson, E. (2016). Enhancing learning and engagement through embodied interaction within a mixed reality simulation. Computers \& Education, 95, 174-187. http://dx.doi.org/10.1016/j.compedu.2016.01.001

Lu, C., \& Montague, B. (2015). Move to learn, learn to move: Prioritizing physical activity in early childhood education programming. Early Childhood Education Journal, 44, 409-417. doi: 10.1007/s10643-015-0730-5

Madan, C. R., \& Singhal, A. (2012). Using actions to enhance memory: effects of enactment, gestures, and exercise on human memory. Frontiers in Psychology, 3, 1-4. http://dx.doi.org/10.3389/fpsyg.2012.00507

Mahar, M. T., Murphy, S. K., Rowe, D. A., Golden, J., Shields, A. T., \& Raedeke, T. D. (2006). Effects of a classroom-based program on physical activity and ontask behavior. Medicine and Science in Sports and Exercise, 38(12), 20862094. doi: 10.1249/01.mss.0000235359.16685.a3 
Mahar, M. T. (2011). Impact of short bouts of physical activity on attention-to-task in elementary school children. Preventive Medicine, 52, S60-S64. http://dx.doi.org/10.1016/j.ypmed.2011.01.026

Mavilidi, M. F., Okely, A. D., Chandler, P., Cliff, D. P., \& Paas, F. (2015). Effects of integrated physical exercises and gestures on preschool children's foreign language vocabulary learning. Educational Psychology Review, 27(3), 413426 doi: 10.1007/s10648-015-9337-z

Mavilidi, M. F., Okely, A. D., Chandler, P., \& Paas, F. (2016). Infusing physical activities into the classroom: Effects on preschool children's geography learning. Mind, Brain, and Education, 10(4), 256-263.

Moreau, D. (2015). Brains and brawn: complex motor activities to maximize cognitive enhancement. Educational Psychology Review, 27(3), 475-482. doi: $10.1007 / \mathrm{s} 10648-015-9323-5$

National Association for Sport and Physical Education, 2002. Active start: a statement of physical activity guidelines for children birth to five years. American Alliance for Health, Physical Education, Recreation and Dance, Reston, VA.

Ogden, C. L., Carroll, M. D., Curtin, L. R., McDowell, M. A., Tabak, C. J., \& Flegal, K. M. (2006). Prevalence of overweight and obesity in the United States, 1999-2004. Journal of American Medical Association, 295(13), 1549-1555. doi: 10.1001/jama.295.13.1549

Owen, K. B., Parker, P. D., Van Zanden, B., MacMillan, F., Astell-Burt, T., \& Lonsdale, C. (2016). Physical Activity and School Engagement in Youth: A Systematic Review and Meta-Analysis. Educational Psychologist, 51(2), 129145. http://dx.doi.org/10.1080/00461520.2016.1151793 
Paas, F., \& Sweller, J. (2012). An evolutionary upgrade of cognitive load theory: Using the human motor system and collaboration to support the learning of complex cognitive tasks. Educational Psychology Review, 24(1), 27-45. doi: $10.1007 / \mathrm{s} 10648-011-9179-2$

Pate, R. R., Almeida, M. J., McIver, K. L., Pfeiffer, K. A., \& Dowda, M. (2006). Validation and calibration of an accelerometer in preschool children. Obesity, 14(11), 2000-2006. doi: 10.1038/oby.2006.234

Penedo, F. J., \& Dahn, J. R. (2005). Exercise and well-being: a review of mental and physical health benefits associated with physical activity. Current Opinion in Psychiatry, 18(2), 189-193.

Piaget, J. (1970). Science of education and the psychology of the child. Trans. D. Coltman.

Plummer, J. D. (2009). Early elementary students' development of astronomy concepts in the planetarium. Journal of Research in Science Teaching, 46(2), 192-209. doi: 10.1002/tea.20280

Pouw, W. T., Van Gog, T., \& Paas, F. (2014). An embedded and embodied cognition review of instructional manipulatives. Educational Psychology Review, 26(1), 51-72. doi: 10.1007/s10648-014-9255-5

Rasberry, C. N., Lee, S. M., Robin, L., Laris, B. A., Russell, L. A., Coyle, K. K., \& Nihiser, A. J. (2011). The association between school-based physical activity, including physical education and academic performance: a systematic review of the literature. Preventive Medicine, 52, S10-S20. http://dx.doi.org/10.1016/j.ypmed.2011.01.027

Rizzolatti, G., \& Craighero, L. (2004). The mirror-neuron system. Annual Review of Neuroscience, 27, 169-192. doi:10.1146/annurev.neuro.27.070203.144230. 
Sallis, J. F., McKenzie, T. L., Alcaraz, J. E., Kolody, B., Faucette, N., \& Hovell, M. F. (1997). The effects of a 2-year physical education program (SPARK) on physical activity and fitness in elementary school students. Sports, play and active recreation for kids. American Journal of Public Health, 87(8), 13281334. doi: 10.2105/AJPH.87.8.1328

Schmidt, M., Benzing, V., \& Kamer, M. (2016). Classroom-based physical activity breaks and children's attention: Cognitive engagement works! Frontiers in Psychology, 7, 1-13. doi: 10.3389/fpsyg.2016.01474

Shoval, E. (2011). Using mindful movement in cooperative learning while learning about angles. Instructional Science, 39(4), 453-466. doi:10.1007/s11251-010$9137-2$

Sibley, B. A., \& Etnier, J. L. (2003). The relationship between physical activity and cognition in children: a meta-analysis. Pediatric Exercise Science, 15(3), 243256

Sothern, M. S., Loftin, M., Suskind, R. M., Udall, J. N., \& Blecker, U. (1999). The health benefits of physical activity in children and adolescents: implications for chronic disease prevention. European Journal of Pediatrics, 158(4), 271274. doi: $10.1007 / \mathrm{s} 004310051070$

Tarp, J., Domazet, S. L., Froberg, K., Hillman, C. H., Andersen, L. B., \& Bugge, A. (2016). Effectiveness of a school-based physical activity intervention on cognitive performance in Danish adolescents: LCoMotion-learning, cognition and motion-A cluster randomized controlled trial. PloS One, 11(6), e0158087. http://dx.doi.org/10.1371/journal.pone.0158087 
Tomporowski, P. D., Davis, C. L., Miller, P. H., \& Naglieri, J.A. (2008). Exercise and children's intelligence, cognition, and academic achievement. Educational Psychology Review, 20, 111-131. doi: 10.1007/s10648-007-9057-0

Tremblay, M. S., LeBlanc, A. G., Carson, V., Choquette, L., Connor Gorber, S., Dillman, C., Duggan, M., Gordon, M. J., Hicks, A., Janssen, I., Kho, M. I., Latimer-Cheung, A. E., LeBlanc, C., Murumets, K., Okely, A. D., Reilly, J. J., Spence, J. C., Stearns, J. A., Timmons, B. W. (2012). Canadian physical activity guidelines for the early years (aged 0-4 years). Applied Physiology, Nutrition, and Metabolism, 37(2), 345-356.

Trost, S. G., Sirard, J. R., Dowda, M., Pfeiffer, K. A., \& Pate, R. R. (2003). Physical activity in overweight and nonoverweight preschool children. International Journal of Obesity, 27(7), 834-839. doi: 10.1038/sj.ijo.0802311

Trundle, K. C. (2015). The inclusion of science in early childhood classrooms. In Research in early childhood science education (pp. 1-6). Springer Netherlands. doi: 10.1007/978-94-017-9505-0_1

Uttal, D. H., Miller, D. I., \& Newcombe, N. S. (2013). Exploring and enhancing spatial thinking links to achievement in science, technology, engineering, and mathematics? Current Directions in Psychological Science, 22(5), 367-373.

Van Gog, T., Paas, F., Marcus, N., Ayres, P., \& Sweller, J. (2009). The mirror neuron system and observational learning: Implications for the effectiveness of dynamic visualizations. Educational Psychology Review, 21(1), 21-30. doi: $10.1007 / \mathrm{s} 10648-008-9094-3$ 
Vazou, S., \& Smiley-Oyen, A. (2014). Moving and academic learning are not antagonists: acute effects on executive function and enjoyment. Journal of Sport \& Exercise Psychology, 36(5), 474-485. doi: 10.1123/jsep.2014-0035

Vazou, S., Pesce, C., Lakes, K., \& Smiley-Oyen, A. (in press). More than one road leads to Rome: A narrative review and meta-analysis of physical activity intervention effects on cognition in youth. International Journal of Sport and Exercise Psychology. http://dx.doi.org/10.1080/1612197X.2016.1223423

Vygotsky, L. (1962). Thought and language. Cambridge, MA: MIT Press.

Warburton, D. E., Nicol, C. W., \& Bredin, S. S. (2006). Health benefits of physical activity: the evidence. Canadian Medical Association Journal, 174(6), 801809. doi: 10.1503/cmaj.051351

Ward, D. S., Saunders, R., Felton, G. M., Williams, E., Epping, J. N., \& Pate, R. R. (2006). Implementation of a school environment intervention to increase physical activity in high school girls. Health Education Research, 21(6), 896910. doi: 10.1093/her/cyl134

Wilson, M. (2002). Six views of embodied cognition. Psychonomic Bulletin \& Review, 9(4), 625-636. doi: 10.3758/BF03196322

World Health Organization. (2015). Physical activity. Retrieved from: http://www. who.int/topics/physical_activity/en/

Zacharia, Z. C., Loizou, E., \& Papaevripidou, M. (2012). Is physicality an important aspect of learning through science experimentation among kindergarten students? Early Childhood Research Quarterly, 27(3), 447-457. http://dx.doi.org/10.1016/j.ecresq.2012.02.004 
Table 1.

Participants' demographics stratified by condition.

\begin{tabular}{|c|c|c|c|c|c|}
\hline & Total & $\begin{array}{l}\text { Integrated } \\
\text { Condition }\end{array}$ & $\begin{array}{c}\text { Non- } \\
\text { integrated } \\
\text { Condition }\end{array}$ & $\begin{array}{c}\text { Control } \\
\text { Condition } \\
\end{array}$ & $\begin{array}{c}\mathrm{P} \\
\text { value }\end{array}$ \\
\hline Age, years (SD) & $4.90(.52)$ & $4.96(.51)$ & $5.10(.43)$ & $4.80(.44)$ & $.118^{\mathrm{a}}$ \\
\hline Gender, $\mathrm{N}$ boys $(\%)$ & 49.4 & 54.8 & 40.7 & 51.7 & $.538^{\mathrm{b}}$ \\
\hline Ethnicity, N Australian (\%) & 74.7 & 90.3 & 70.4 & 62.1 & $.269^{b}$ \\
\hline $\begin{array}{l}\text { Health Care Card or } \\
\text { Pension card, N no }(\%)^{\mathrm{c}}\end{array}$ & 92 & 96.6 & 85.2 & 93.5 & $.284^{\mathrm{b}}$ \\
\hline
\end{tabular}


Table 2.

Means and Standard Deviations for Performance and Instruction Evaluation at the Immediate and Delayed Tests as a Function of the Condition.

\begin{tabular}{lcc}
\hline & Performance & Evaluation \\
Time of testing & $\mathrm{M}(\mathrm{SD})$ & $\mathrm{M}(\mathrm{SD})$ \\
\hline Pre-test scores $(0-28)$ & $1.58(1.67)$ & \\
Integrated condition & $1.37(1.82)$ & \\
Non-integrated condition & $1.55(2.72)$ & \\
Control condition & & \\
Immediate post-test (0-28) & $15.53(4.91)$ & $4.35(1.05)$ \\
Integrated condition & $11.07(5.04)$ & $3.98(.91)$ \\
Non-integrated condition & $5.52(4.37)$ & $3.67(1.17)$ \\
Control condition & & \\
Delayed post-test (0-28) & $12.63(5.08)$ & $4.37(.82)$ \\
Integrated condition & $8.97(4.14)$ & $3.91(1.00)$ \\
Non-integrated condition & $5.14(3.36)$ & $3.31(.88)$ \\
Control condition & & \\
\hline
\end{tabular}




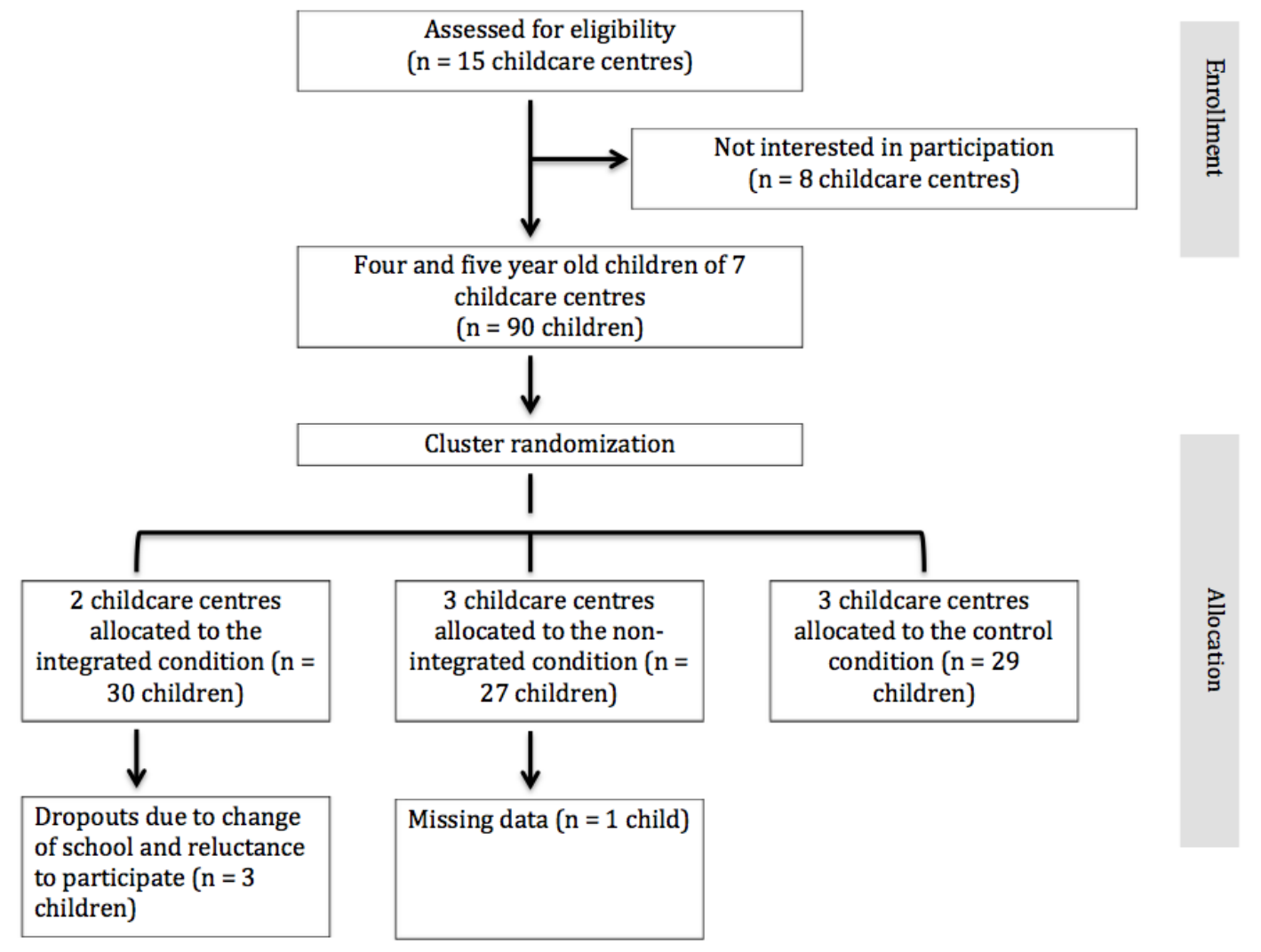

Figure 1. Chart flow of schools and children from enrolment and allocation. 